\title{
Genetic causes of acute encephalopathy in adults: beyond inherited metabolic and epileptic disorders
}

\author{
Dimitrios Parissis $^{1} \cdot$ Maria Dimitriou ${ }^{1} \cdot$ Panagiotis loannidis $^{1}$
}

Received: 16 August 2021 / Accepted: 13 January 2022 / Published online: 22 January 2022

(c) Fondazione Società Italiana di Neurologia 2022

\begin{abstract}
Acute encephalopathy is a widely used term, implying a rapidly progressive multifocal or diffuse brain dysfunction, caused by acute structural disturbance or a myriad of metabolic, toxic, epileptic, or infection-related factors. Apart from the more common acquired causes, a broad range of rare inherited disorders may produce spells of encephalopathy in adulthood, posing diagnostic challenges to clinicians. Among the latter, neurometabolic disorders and epileptic syndromes constitute typical examples. Interestingly, certain genetic entities have the potential to provoke episodic changes of cognition, via alternative, neither metabolic nor epileptic, mechanisms. Our aim is to provide a short and focused overview of their clinicoradiological features and potential pathophysiology. As the neurogenetic landscape is rapidly evolving, it is important to be familiar with these chameleons, in order to provide swift diagnosis and proper genetic counselling.
\end{abstract}

\section{Highlights}

- Approaching a patient with episodic impairment of consciousness is one of the most demanding tasks in the field of clinical neurology.

- After excluding common and uncommon acquired causes of acute encephalopathy, one should always think of the genetic variants.

- Among the latter, encephalopathies of metabolic origin due to enzymatic deficiency or mitochondrial dysfunction are commonly analyzed in the literature.

- Certain genetic diseases without evidence of metabolic alteration or epileptic component should also be considered in differential diagnosis, principally in terms of genetic counselling and preventing, or treating disabling attacks.

Keywords Encephalopathy $\cdot$ Metabolic disease $\cdot$ Paroxysmal disorder $\cdot$ Genetic

\section{Introduction}

The term encephalopathy stems from the Greek word

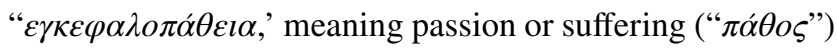
of the brain (" $\varepsilon \gamma \kappa \varepsilon ́ \varphi \alpha \lambda o \varsigma$ "). Recently, a task force group of experts from ten academic societies provided a consensusbased, uniform nomenclature in the field of acute cognition disturbances [1]. They recommended that the term acute encephalopathy should be considered as a rapidly

Maria Dimitriou

dimitrioumariad@gmail.com

2nd Department of Neurology, Aristotle University of Thessaloniki, AHEPA Hospital, Stilp. Kyriakidi 1, 54636 Thessaloniki, Greece developing pathophysiological brain process, which may be expressed as either subsyndromal delirium, delirium, or coma [1]. According to this position statement, subsyndromal delirium refers to an intermediate state between normal cognition and delirium, where not all DSM-5 criteria for delirium are fulfilled.

We would like to clarify that the epileptic encephalopathies of genetic origin are beyond the scope of this review, since they constitute a conceptually distinct group of disorders, necessitating separate study. In these cases, the epileptiform activity itself is the fundamental factor in the development of mental impairment or developmental regression beyond what might be anticipated from the responsible pathology [2]. In other words, the term epileptic encephalopathy refers mostly to the long-term cognitive consequences of a catastrophic epileptic disorder. 
Among causes of encephalopathy, inherited metabolic disorders represent major culprits, emphatically in neonates, infants, and children [3]. In particular, organic acidurias, beta-oxidation defects, aminoacidopathies, homocysteine remethylation defects, and biotin-thiamineresponsive basal ganglia disease have all been associated with relapses of disturbed consciousness [4, 5]. Adult neurologists may similarly face exceptional cases of delirium or coma in the context of a genetic metabolic abnormality. Classic examples comprise urea cycle disorders (e.g., due to ornithine transcarbamylase deficiency) and hepatic porphyrias (e.g., due to porphobilinogen deaminase deficiency) (Table 1) [6, 7]. In these paradigms, the biochemical defect becomes neurologically apparent, whenever an identifiable precipitant, such as an increased protein load; a physiological stress, such as an intercurrent illness or surgery; or certain medications, induces a substantial metabolic decompensation [3].

Over the past years, it became apparent that various diseases having a diverse genetic substrate may lead to acute encephalopathy in adults without evidence of metabolic or epileptic component that could explain this presentation. Unraveling these disorders represents a diagnostic challenge, given their rarity and clinician unfamiliarity. To our knowledge, there has been no focused and comparative review of their characteristics. Our ambition is to fill in this gap in the literature (Tables 2 and 3), rendering them more easily identifiable in neurological practice.

Table 1 Inherited, metabolic disorders with potential to cause acute encephalopathy in adults

\begin{tabular}{|c|c|c|c|c|}
\hline & Wilson's disease & Acute porphyrias & Urea cycle disorders & $\begin{array}{l}\text { Biotin-responsive basal ganglia } \\
\text { disease }\end{array}$ \\
\hline Age & $\begin{array}{l}\text { Children } \\
\text { Young adults }\end{array}$ & Young adults & $\begin{array}{l}\text { Infancy, children } \\
\text { Rarely in adults }\end{array}$ & $\begin{array}{l}\text { Infancy, children } \\
\text { Rarely in adults }\end{array}$ \\
\hline Gene(s) & ATP7B & $\begin{array}{l}\text { HMBS, PPOX, CPOX, } \\
\text { ALAD }\end{array}$ & $\begin{array}{l}\text { CPS1, OTC, ASS1, ASL, } \\
\text { SLC25A15 }\end{array}$ & SLC19A3 \\
\hline $\begin{array}{l}\text { Encephalopa- } \\
\text { thy character- } \\
\text { istics }\end{array}$ & $\begin{array}{l}\text { Hepatic encephalopathy in } \\
\text { the setting of acute liver } \\
\text { failure }\end{array}$ & $\begin{array}{l}\text { In up to } 70 \% \text { of porphyric } \\
\text { attacks } \\
\text { May simulate PRES }\end{array}$ & $\begin{array}{l}\text { Often triggered by protein } \\
\text { load or stress } \\
\text { Hyperammonemic crisis }\end{array}$ & $\begin{array}{l}\text { Resembles Wernicke-type } \\
\text { encephalopathy }\end{array}$ \\
\hline Prognosis & Poor & Good & Good if treated & Good \\
\hline Treatment & Liver transplantation & $\begin{array}{l}\text { I.V. hemin } \\
\text { Symptomatic, prophylaxis }\end{array}$ & $\begin{array}{l}\text { Hemodialysis } \\
\text { Sodium benzoate Prophylaxis }\end{array}$ & $\begin{array}{l}\text { Biotin-thiamine supplementa- } \\
\text { tion } \\
\text { Symptomatic }\end{array}$ \\
\hline
\end{tabular}

$A T P 7 B$ ATPase copper transporting beta, $H M B S$ hydroxymethylbilane synthase, $P P O X$ protoporphyrinogen oxidase, $C P O X$ coproporphyrinogen oxidase, $A L A D$ aminolevulinate dehydratase, CPS1 carbamoyl-phosphate synthase 1, OTC ornithine transcarbamylase, ASS1 argininosuccinate synthase $1, A S L$ argininosuccinate lyase, PRES posterior reversible encephalopathy syndrome.

Table 2 Summary of the main clinical features of the encephalopathy attacks in inherited, non-metabolically related, disorders

\begin{tabular}{|c|c|c|c|c|c|c|c|c|c|}
\hline & VWM & NIID & CADASIL & CMTX & FHM & ANE & HLH & $\begin{array}{l}\text { MELAS/ } \\
\text { POLG }\end{array}$ & MERS \\
\hline Age & $\begin{array}{l}1-8 \text { years } \\
\text { peak } \\
20 \% \text { teens- } \\
\text { adults }\end{array}$ & Adults & $\begin{array}{l}\text { Young to } \\
\text { mid-age } \\
\text { adults }\end{array}$ & $\begin{array}{l}\text { Children- } \\
\text { young } \\
\text { adults }\end{array}$ & Youth & $\begin{array}{l}\text { Children } \\
\text { Young adults }\end{array}$ & All ages & $\begin{array}{l}\text { Children } \\
\text { Adults }\end{array}$ & All ages \\
\hline Trigger & $\begin{array}{l}\text { Inf, head } \\
\text { injury } \\
\text { Anesthesia }\end{array}$ & None & None & $\begin{array}{l}\text { High altitude } \\
\text { Infection }\end{array}$ & $\begin{array}{l}\text { Head trauma } \\
\text { Angiography }\end{array}$ & Viral inf & Inf & $\begin{array}{l}\text { Inf, dehydra- } \\
\text { tion, fasting, } \\
\text { seiz }\end{array}$ & $\begin{array}{l}\text { Viral, } \\
\text { metabolic } \\
\text { disease }\end{array}$ \\
\hline Relapses & $\mathrm{y}$ & - & $\mathrm{y}$ & $\mathrm{y}$ & $\mathrm{y}$ & $\mathrm{y}$ & - & $\mathrm{y}$ & Rare \\
\hline Prognosis & Poor & Unknown & Excellent & Excellent & Moderate & Moderate & Poor & Moderate & Good \\
\hline Treatment & None & Steroids? & Symptomatic & None & $\begin{array}{l}\text { Symptomatic } \\
\text { prophylaxis }\end{array}$ & $\begin{array}{l}\text { Steroids- } \\
\text { IVIG }\end{array}$ & $\begin{array}{l}\text { Steroids } \\
\text { HCT }\end{array}$ & $\begin{array}{r}\text { Symptomatic } \\
\text { prophylaxis }\end{array}$ & Symptomatic \\
\hline
\end{tabular}

ANE acute necrotizing encephalopathy; CADASIL cerebral autosomal dominant arteriopathy with subcortical infarcts and leukoencephalopathy; CMTX X-linked Charcot-Marie-Tooth disease; FHM familial hemiplegic migraine; HCT hematopoietic cell transplantation; $H L H$ hemophagocytic lymphohistiocytosis; Inf infections; MERS mild encephalitis/encephalopathy with a reversible splenial lesion; NIID neuronal intranuclear inclusion disease; MELAS/POLG mitochondrial encephalopathy; lactic acidosis and stroke-like episodes/polymerase gamma disease; seiz seizures, $V W M$ vanishing white matter disease. 
Table 3 Genetic aspects of non-metabolic diseases leading to acute encephalopathy

\begin{tabular}{|c|c|c|c|c|}
\hline Disorder & Gene(s) & Molecular pathogenesis & Inheritance & Estimated prevalence \\
\hline MELAS & $\begin{array}{l}\text { mtDNA (typically MT-TL1 and } \\
\text { MT-ND5); other mt DNA } \\
\text { genes }\end{array}$ & $\begin{array}{l}\text { Decreased function of res- } \\
\text { piratory chain complexes or } \\
\text { constituent subunits }\end{array}$ & Mitochondrial & $\begin{array}{l}\text { Varies between population } \\
\text { (i.e., 16:100,000 in Finland) }\end{array}$ \\
\hline POLG-related disease & POLG & $\begin{array}{l}\text { Disturbance of mtDNA replica- } \\
\text { tion }\end{array}$ & Autosomal recessive & 1:10,000 (Northern Europe) \\
\hline CADASIL & NOTCH3 & $\begin{array}{l}\text { Aggregation of mutant } \\
\text { NOTCH3 protein in cerebral } \\
\text { vasculature }\end{array}$ & Autosomal dominant & $\begin{array}{l}\text { 5:100,000 } \\
\text { (underdiagnosed) }\end{array}$ \\
\hline CMTX & GJB1 & $\begin{array}{l}\text { Reduced efficiency of gap junc- } \\
\text { tions between oligodendro- } \\
\text { cytes and astrocytes in CNS }\end{array}$ & X-linked & $2: 100,000$ \\
\hline VWM & EIF2B1-5 & $\begin{array}{l}\text { Dysfunction of the cellular } \\
\text { stress response pathway }\end{array}$ & Autosomal recessive & $1,4: 1,000,000$ \\
\hline FHM & CACNA1A, ATP1A2, SCN1A & $\begin{array}{l}\text { Increased susceptibility to cor- } \\
\text { tical spreading depression }\end{array}$ & Autosomal dominant & 3: 100.000 \\
\hline NIID & $\begin{array}{l}\text { NOTCH2NLC (repeat expan- } \\
\text { sion) }\end{array}$ & $\begin{array}{l}\text { Accumulation of intranuclear } \\
\text { ubiquitinated neuronal inclu- } \\
\text { sions }\end{array}$ & Autosomal dominant & $\begin{array}{l}\text { Unknown, possibly restricted } \\
\text { to East Asian populations }\end{array}$ \\
\hline ANE & RANBP2 & $\begin{array}{l}\text { Altered immune response to } \\
\text { viruses }\end{array}$ & Autosomal dominant & Unknown, mostly in East Asia \\
\hline HLH & $\begin{array}{l}\text { PRF1, STX11, STXBP2, } \\
\text { UNC13D }\end{array}$ & $\begin{array}{l}\text { Deficiency in cytotoxic path- } \\
\text { ways }\end{array}$ & Autosomal recessive & $1: 100,000$ \\
\hline MERS & MYRF & Myelin vacuolization & Autosomal recessive & Extremely rare \\
\hline
\end{tabular}

MELAS mitochondrial encephalopathy, lactic acidosis, and stroke-like episodes; POLG polymerase gamma; CADASIL cerebral autosomal dominant arteriopathy with subcortical infracts and leukoencephalopathy; $C M T X$ X-linked Charcot-Marie-Tooth disease; VWM vanishing white matter disease; FHM familial hemiplegic migraine; NIID neuronal intranuclear inclusion disease; $A N E$ acute necrotizing encephalopathy; $H L H$ hemophagocytic lymphohistiocytosis; MERS mild encephalitis/encephalopathy with a reversible splenial lesion.

\section{Methods}

Data for this review were obtained by searches of MEDLINE for references of relevant articles. Search terms used were "encephalopathy", "acute encephalopathy", "coma", "stupor", "adulthood", "metabolic disease", "inborn errors of metabolism", "inherited metabolic disorders", "genetic encephalopathies". Results were then screened for potentially relevant studies by application of inclusion and exclusion criteria for the full texts of the papers. Randomized controlled trials; observational, controlled studies of case series; and case reports were included. Only original, peer-reviewed articles about humans published in English between 1975 and 2020 were analyzed. Reviews and editorials were also considered. Websites checked for additional, particularly genetic information, were the following:

Neuromuscular homepage: https://neuromuscular. wustl.edu/ and.

Genetics Home Reference: https://doi.org/10.1016/j. jns.2019.03.021

\section{Vanishing white matter disease}

Leukoencephalopathy with vanishing white matter (VWM) is an autosomal recessive disease caused by mutations in any of the five EIF (eukaryotic initiating factor) 2B genes [8]. Several lines of evidence suggest that VWM represents a developmental disorder of glial cells driven by astrocytic pathology [9]. VWM leads to progressive motor, cognitive, and psychiatric disability, along with seizures, whereas brain imaging discloses a distinct pattern of abnormalities, namely, cystic-like regions (hypointense on T1 and FLAIR) evoked by rarefaction of white matter within confluent areas of T2 supratentorial hyperintensities [8, 10].

The disease affects predominantly infants and young children; however, adolescent and adult onset are remarkable in approximately $25 \%$ of all cases [11]. A defining characteristic of VWM that facilitates its recognition from other leukodystrophies is the occurrence (even at the outset of the disease) of discrete episodes of neurological deterioration superimposed on a background of chronic progressive course $[11,12]$. According to natural history data from 
multicenter, longitudinal studies, the episodes involve motor problems and cognitive disturbance, whereas in nearly $60 \%$ of cases they consist of confusion or coma [11, 12]. Typical provoking factors of these crises in descending order of frequency include febrile illness, minor head injury, subclinical infections, anesthesia, acute psychologic stress, hyperthermia, and seizures [8-10].

Recent progress in the understanding of VWM pathomechanisms suggests that this selective susceptibility to various stimuli is mediated by the dysregulation of the integrated stress response, caused by the EIF2B mutations [13]. We emphasize that acute events in VWM are commonly followed by severe handicaps or, in rare cases, even death. Therefore, treating neurologists, who may examine adolescents or adults with genetically confirmed VWM, should focus on the primary prevention and/or early symptomatic treatment of the attacks.

\section{Cerebral autosomal dominant arteriopathy with subcortical infarcts and leukoencephalopathy (CADASIL)}

Most clinical neurologists are familiar with this genetic vascular leukoencephalopathy, characterized by mid-adult onset of recurrent ischemic strokes and cognitive impairment progressing to dementia. Useful pointers to a probable CADASIL diagnosis is a positive personal history of migraine with aura and the indicative imaging findings of small vessel angiopathy, including prominent involvement of the anterior temporal pole and the external capsule [14]. Typically, CADASIL is caused by missense mutations of the NOTCH 3 gene, producing a cysteine amino acid change in one of the epidermal growth factor repeat domain of the extracellular part of the NOTCH 3 protein $[14,15]$.

Interestingly, a minority of CADASIL patients exhibits episodes of acute and reversible encephalopathy, as first suggested by case reports published in 2002 [16, 17]. Subsequently, the term CADASIL coma was coined to these events by Schon et al [18]. In their series of patients, six out of 70 individuals presented with an encephalopathy, originally perceived as acute encephalitis.

Recently, the clinical features, risk factors, neuroimaging correlates, and prognosis of CADASIL encephalopathy from a large British cohort have been delineated. In agreement with the previous mentioned study, acute events affected nearly $10 \%$ of the population studied. In sharp contrast to VWM, no specific provoking factors were identified [15].

Migrainous symptoms prevail at the onset of the deteriorating events and gradually give rise to consciousness alteration of variable level. The encephalopathy period is then dominated by focal neurological signs, mostly of cortical origin, and less frequently by visual hallucinations and epileptic seizures. Unlike VWM, complete recovery is observed within 1-3 months in the vast majority of patients, whereas relapses are noted in one-third of them. Regarding neuroimaging, no overt signs of ischemic changes were detected during the acute phase of the encephalopathy period. Of note, a minority of MR studies revealed focal cortical swelling indicating mild cerebral edema [15].

According to this study, a past history of migraine with aura is the major risk factor for the development of encephalopathy. Overall, the close association with migraine provides some indirect evidence that mechanisms, such as cortical spreading depression, might be implicated, although the exact pathophysiology is currently unknown [19].

\section{Neuronal intranuclear inclusion disease}

Neuronal intranuclear inclusion disease (NIID) is a slowly progressive neurodegenerative disorder defined pathologically by the presence of eosinophilic hyaline intranuclear inclusions in the central, peripheral, and autonomic neurons [20]. NIID has a wide clinical spectrum consisting of cognitive problems, cerebellar ataxia, pyramidal-extrapyramidal signs, peripheral neuropathy, and autonomic dysfunction. Until recently, the chance of diagnosing NIID during life was small, because of its protean clinical manifestations, the absence of reliable biomarkers and the absolute need to proceed to invasive procedures, such as brain biopsy [21].

Fortuitously, a multicenter study from Japan confirmed earlier observations that skin biopsy may enable ante mortem diagnosis of NIID by identifying inclusion in adipocytes and sweat gland cells morphologically and immunohistochemically identical to those found in the CNS [21-23].

In the above-mentioned study of 57 adult NIID cases, those with sporadic disease had invariably developed dementia, whereas neuropathy was the prominent manifestation in the younger, familial subgroup of patients. Notably, $20 \%$ of sporadic NIID patients suffered subacute encephalitic-like episodes, composed of fever, vomiting, and confusion. Some of these patients showed focal brain edema and gadolinium enhancement on MR scans, while they benefited moderately from steroid pulse therapy [21]. Whereas the nature of these episodes is unclear, Fujita et al. reported on SPECT perfusion changes similar to those found during migraine with aura in a single NIID case [24].

It is also of major clinical importance that the vast majority of NIID subjects demonstrate a selective pattern of high signal abnormality on diffusion-weighted images involving the $\mathrm{U}$ fibers along the corticomedullary junction, thus facilitating NIID diagnosis [21, 22]. With the advent of human genetics and the recent discovery of a novel trinucleotide repeat expansion in the human-specific NOTCH2NLC gene as the genetic background of NIID, we believe that this disorder will be more frequently identified in neurology clinics $[25,26]$. 


\section{X-linked Charcot-Marie-Tooth disease}

X-linked Charcot-Marie-Tooth (CMTX1), emerged as one of the most prevalent subtypes of CMT disease, is caused by pathogenic variants in GJB1 gene encoding connexin 32 (Cx32) [27]. It has been clearly documented in the literature that a significant minority of CMTX1 patients may, in addition, display signs of CNS dysfunction, detected through clinical, radiological, or neurophysiological testing [28-31]. Furthermore, subjects carrying certain mutations of GJB1 gene are prone to develop stroke or ADEM-like episodes comprising transient hemiparesis, paraparesis, quadriparesis, ataxia, dysarthria, and dysphasia [31-34]. These fully reversible symptoms have been consistently linked with diverse triggers, like traveling to high altitude, febrile illness, trauma, and hyperventilation. CNS events tend to be more common in children and young adults without any correlation with the stage and severity of the peripheral neuropathy [31].

Short-term or persistent confluent areas of T2 high signal in the deep white matter and more rarely in the corpus callosum, occasionally showing restricted diffusion, constitute the radiological accompaniments of the episodes [27, 31]. From a pathophysiological point of view, in vivo and in vitro disease models have indicated that the disruption of gap junction-mediated interaction between oligodendrocytes and astrocytes likely leads to an inability of these cells to regulate ion and fluid exchange, thereby contributing to the CNS phenotype [27, 31].

We would also like to comment that the commonly used term "encephalopathy" in the context of CMTX1 is probably a misnomer, because, to our knowledge, no convincing case, fulfilling strict diagnostic criteria for encephalopathy, has been described.

\section{Mild encephalitis/encephalopathy with a reversible splenial lesion}

Mild encephalitis/ encephalopathy with a reversible splenial lesion (MERS) is a recently recognized subtype of acute encephalopathy [35]. Patients typically present with altered consciousness and/or delirious behavior, lasting for several days to weeks. The disturbance in mental status is thought to result from functional disconnection between cerebral hemispheres, whereas the prognosis is fairly good with complete resolution of the associated imaging abnormalities [35, 36].

The radiological hallmark of MERS, as its name implies, consists of lesions restricted to the splenium of the corpus callosum, which occasionally have the potential to expand to the nearby subcortical white matter, showing restricted diffusion on MR imaging [36, 37]. One hypothesis states that various conditions (viral infections, metabolic disorders, etc.) associated with uncontrolled cytokine and glutamate release can cause disproportionate damage to the corpus callosum fibers, with the eventual development of cytotoxic, intramyelinic edema [37].

Interestingly, Kurahashi et al. provided preliminary evidence that genetic factors may contribute to this syndrome, at least in those cases where positive family history and relapsing/remitting course co-exist. They identified patients with familial MERS and extensive leukoencephalopathy, harboring mutations in the gene coding myelin regulator factor (MYRF), an essential component of oligodendrocyte differentiation and myelin maintenance [38]. Not surprisingly, MYRF and Cx32 possess similar biologic properties, acting in concert for the integrity of the myelin sheath [38]. This knowledge could possibly interpret the analogies between MERS and the CNS phenotype of CMTX1.

\section{Hemiplegic migraine}

It has been demonstrated since the early 1980s that patients with hemiplegic migraine may suffer from impaired consciousness during their attacks [39-41]. Indeed, a recent nationwide Dutch study found confusion to be a regular accompaniment of the ordinary migraine paroxysms, especially in subjects carrying mutations in the three genes etiologically related to the familial type of hemiplegic migraine [42]. CACNA1A, encoding the pore-forming subunit of neuronal P/Q-type calcium channels; ATP1A2, responsible for the catalytic subunit of a glial and neuronal sodium-potassium pump; and SCN1A, encoding the pore forming subunit of neuronal $\mathrm{Na}_{\mathrm{v}} 1.1$ sodium channels, are ion transportation genes, critical for the maintenance of neuronal excitability and synaptic transmission [41]. Fever and seizures were also not uncommon in the above case series.

Earlier studies have estimated that debilitating attacks, unique to familial hemiplegic migraine, leading to profound coma of several days to weeks duration, may affect up to one-third of patients with CACNA1A mutation and 15\% of ATP1A2 variants [43, 44]. Notably, major episodes of encephalopathy were extremely rare in the Danish population-based sample, which mainly included families lacking these mutations [45].

Clinical investigations frequently indicate CSF pleocytosis, cortical edema, and transient meningeal gadolinium enhancement, exclusively in cases of severe attacks, mimicking acute encephalitis. It is also clear that brain ischemia does not contribute to the phenotype.

The prognosis of the episodes is generally favorable, although fixed deficits or even death, exceptionally do occur. Minor head trauma, in analogy to VWM, appears to be a common precipitating factor of the attacks, whereas pregnancy and catheter angiography are similarly capable to uncover the genetic trait [40-43]. It is also of interest that a specific CACNA1A mutation (e.g., S218L) has the 
particular potential to induce fulminant encephalopathy with early seizures and cerebral edema after trivial head injury [46]. Cellular and animal studies revealed that this dramatic phenotype is probably mediated by a pronounced effect of S218L on the threshold of cortical spreading depression initiation [47].

\section{Acute necrotizing encephalopathy}

Acute necrotizing encephalopathy (ANE) is a rare and catastrophic type of encephalopathy affecting previously healthy children following a viral infection, such as influenza-A, herpes simplex virus, influenza-B, mycoplasma, and human herpes virus-6 [48]. Recently, SARS-CoV-2 has also been implicated [49]. ANE has a worldwide distribution with marked emphasis in the East [48]. According to Wu et al, who proposed diagnostic criteria for this disorder, patients demonstrate rapidly progressive consciousness alteration in association with convulsions and, sometimes, severe neurological deficits [50]. Clinical sequelae vary from complete recovery to death, whereas brain imaging reveals distinctive, but not pathognomonic, symmetric lesions in the basal ganglia, thalamus and brainstem, reminiscent of those seen in mitochondrial disorders, e.g. in Leigh syndrome [51, 52]. An interesting imaging feature that can further facilitate the recognition of ANE is the trilaminar sign of the thalamic lesions on DWI and ADC sequences, created by a multilayered appearance of the underlying oedema and the presence of haemorrhagic foci [53].

The majority of cases are sporadic; however, case reports of familial occurrence with a tendency to recur, even in adulthood, led to the identification of the genetic subtype of this disorder, known as acute infection-induced encephalopathy 3 , caused by a pathogenic dominant mutation in the RANBP2 (Ran Binding Protein 2) gene [51, 54]. In the genetic subtype, the MRI changes show a slightly different distribution in the external capsules, claustrum, limbic structures, and temporal lobes [52]. Interestingly, mutations in SCN1A, SCN2A, and RHOBTB2 genes can similarly confer susceptibility to post viral necrotizing encephalopathy [55]. Further discussion of these conditions is beyond the scope of this review.

The postulated mechanisms of this fulminant encephalopathy, either of the genetic or acquired form, may relate to aberrant immunological response, although yet unclear [51]. Clinical neurologists should take ANE into account, whenever a major encephalopathy with compatible brain imaging develops after a viral respiratory prodrome. In the appropriate clinical setting, next-generation sequencing testing may potentially benefit the proband and his family members, offering the opportunity for preventative vaccinations and prompt intervention in the early stages of the illness.

\section{Hemophagocytic lymphohistiocytosis}

Hemophagocytic lymphohistiocytosis (HLH) is an uncommon, but frequently fatal, systemic inflammatory syndrome associated with diverse conditions, such as autoimmune, neoplastic, infectious or hereditary diseases [56]. It is thought that the common denominator of genetically determined and acquired HLH is a cytokine storm in the setting of defective natural killer/T cell function in the cytotoxic pathway having devastating consequences, such as end-organ failure and death if untreated [57]. The most commonly implicated genes in individuals with HLH are PRF1 and UNC13D, whereas a number of eponym immunodeficiency syndromes, e.g., Chediak-Higashi and Hermansky-Pudlak, have been linked to the development of HLH [57, 58].

Overall, CNS involvement has been reported in 30-75\% of all HLH patients, either at presentation or during the course of the disease [58, 59]. Seizures and encephalopathy are the prevailing features followed by meningism and focal neurological signs. Valuable biologic markers favoring a diagnosis of HLH include peripheral cytopenias, hypertriglyceridemia, extreme elevation of ferritin, splenomegaly, and variable detection of hemophagocytes in blood or CSF. Neuroimaging depicts multifocal or confluent inflammatory lesions resembling ADEM, small vessel vasculitis, and CLIPPERS syndrome [58-60]. It is also intriguing the recent study of Benson et al. who reported on four patients with germline mutations in known HLH genes and exclusive CNS-restricted inflammation without involvement of the systemic compartment [60].

HLH can also be thought of as an endpoint of excess immune activation in the setting of systemic autoinflammatory disorders (SAIDs), which are mediated by dysregulation of the innate immune system [61]. Improvement in genetic tools has led to an increased identification of monogenic SAIDs in the adult population, like familial Mediterranean fever (FMF), cryopyrin-associated periodic syndromes (CAPS), and tumor necrosis factor receptor-associated periodic syndrome (TRAPS). Apart from their relation to HLH, autoinflammatory syndromes can have diverse neurological manifestations, mostly in the form of recurrent aseptic meningitis or meningoencephalitis, sensorineural hearing loss, and peripheral neuropathy [61].

HLH, including its genetic subtype, should be incorporated into the differential diagnosis of treatment refractory or recurrent CNS inflammation of uncertain etiology, since early detection and implementation of proper treatment (e.g., use of hematopoietic stem cell transplantation) may prevent irreversible neurological damage [60]. 


\section{Mitochondrial encephalopathies}

Mitochondrial diseases arise as a result of mutations in either the mitochondrial genome per se or nuclear encoded genes involved in mitochondrial homeostasis and function [62]. Apart from a steady, progressive trajectory of peripheral and central nervous system dysfunction, a limited number of mitochondrial disorders may follow an acute or subacute course in the form of stroke-like episodes (SLEs) [63]. According to the recently published International Classification of Inherited Metabolic Disorders, mitochondrial diseases belong to their spectrum; despite this fact, we decided to include them to this review, because SLEs are not simply generated by the accumulation of an intermediate by-product of metabolism, but by the complex interplay of multiple heterogeneous factors, discussed below.

In a seminal paper, Hirano et al. defined SLEs as hallmarks of the syndrome of mitochondrial encephalopathy, lactic acidosis, and stroke-like episodes (MELAS), generally caused by pathogenic variants in the mitochondrial gene MT-TL1 [64]. Besides MELAS, genetic variants in the nuclear POLG (polymerase gamma) gene, an essential component for the replication and repair of the mitochondrial DNA, have been consistently associated with acute encephalopathy. Using a large cohort of 155 patients with POLG-related disease in a multinational study, Hikmat et al. identified SLEs to be a common phenotypic feature in children and young adults below the age of 40 [65]. These cases, clinically indistinguishable from MELAS, may occur in the context of MEMSA (myoclonus, epilepsy, myopathy, and sensory ataxia) spectrum, formerly known as MSCAE (mitochondrial spinocerebellar ataxia with epilepsy) [65, 66]. Recently, a MELAS/Leigh overlap syndrome featuring SLEs due to mutations in the mtDNA genes MT-ND3 and MT-MD5 has been recognized, affecting exclusively young children [67].

Recently, a panel of experts provided consensus-based criteria of these acute events [68]. Briefly, they consist of abnormal level of consciousness ranging from lethargy to coma, focal, or generalized seizure activity, sometimes in the form of epilepsia partialis continua or overt status epilepticus, and focal motor deficits $[66,68,69]$. The episodes are commonly accompanied by migrainous features and severe cortical visual disturbances.

Apart from clinical similarities, SLEs in MELAS and MEMSA share several imaging and neuropathological findings. In particular, posterior brain regions (occipitotemporal in MELAS, mostly occipital in MSCAE) are especially vulnerable to the pathologic process, which manifests confluent edema in cortical and subcortical structures that span arterial territories [70]. In the majority of diffusion-weighted imaging studies, early cytotoxic edema is evident in the first few days of the attacks gradually evolving to extracellular vasogenic edema, as cells undergo lysis and leak their contents [66, 71].

In the acute to subacute phase, brain MRI lesions closely resemble the defining abnormalities of posterior reversible encephalopathy syndrome (PRES) [72]. It appears that in the absence of the known predisposing conditions for PRES, neurological and radiological signs suggestive of PRES, warrant consideration of a possible underlying mitochondrial disorder [72]. Finally, the morphological equivalent of the episodes, known as strokelike lesion (SLL), may either regress or expand reflecting the dynamic course of the pathobiological process [69, 71].

In regard to neuropathology, post-mortem studies of the affected cerebral tissue (SLL) have revealed sharply demarcated lesions with selective but incomplete neuronal loss, eosinophilic necrosis, and microglial activation, whereas microvascular network remains patent $[66,73$, 74]. Cortical laminar necrosis is also observed, highlighting the role of energy failure in the pathogenesis $[66,73]$.

We underline that a similar phenotype of SLEs has also been rarely reported in the context of various other mitochondrial disorders caused by mutations of the mitochondrial or nuclear genome [75-79]. In sharp contrast to MELAS, the attacks do not belong to their fundamental manifestations [69, 71].

The pathophysiology of events underlying the development and progression of the SLLs is currently a matter of debate in the literature [80]. The prevailing, non-mutually exclusive, theories include metabolic disruption, vascular abnormalities, and epileptic factors [66, 68, 69, 71, 81]. It seems that the already metabolically challenged neurons by the respiratory chain dysfunction are vulnerable to the high energy demands posed by seizures, which result in further neuronal injury $[66,68]$. This could provoke sustained ictal activity, perpetuating a vicious cycle that ends-up with a focal energy-dependent neuronal necrosis $[68,73]$. In this regard, anti-epileptic prophylaxis has been recommended, at least for patients harboring POLG recessive mutations, who may suffer debilitating attacks [68].

Population studies from the UK and elsewhere have clarified that MELAS and POLG-related disease are not exotic causes of acute encephalopathy in the adult population $[65,82,83]$. Accordingly, neurologists could play a significant role in the establishment of a prompt diagnosis of mitochondrial disease. This might have important practical implications, not only from a prognostic perspective, but also in relation to therapeutic strategies (e.g., avoidance of sodium valproate in POLG disease, use of substances with potential benefit, and participation in clinical trials for novel therapies). 


\section{Declarations}

Ethics approval None.

Conflict of interest None.

\section{References}

1. Slooter A, Otte W, Devlin J, Arora R, Bleck T, Claassen J, Duprey M, Wesley Ely E, mKaplan P, Latronico N, Morandi A, Neufeld A, Sharshar T, MacLullich A, Stevens R (2020) Updated nomenclature of delirium and acute encephalopathy: statement of ten Societies. Intensive Care Med 46:1020-1022

2. Scheffer I, Berkovic B, Capovilla G, Connolly M, French J, Guilhoto L, Hirsch E, Jain S, Mathern G, Moshé S, Nordli D, Perucca E, Tomson T, Wiebe S, Zhang Y, Zuber S (2017) ILAE classification of the epilepsies: position paper of the ILAE Commission for Classification and Terminology. Epilepsia 58(4):512-521

3. Kwon JM (2018) Testing for Inborn Errors of Metabolism. Contin Neurol 24(Issue 1):37-56

4. Vockley J, Zschocke J, Knerr I. Branched chain organic acidurias. In: Valle D, Beaudet AL, Vogelstein B, et al, eds. The online metabolic and molecular bases of inherited disease. New York, NY: McGraw-Hill, 2014. Accessed April 8, 2020.

5. Kwon JM, D'Aco KE (2013) Clinical neurogenetics: neurologic presentations of metabolic disorders. Neurol Clin 31(4):1031-1035

6. O’Malley R, Ganesh R, Stein P et al (2018) Porphyria: often discussed but too often missed. Pract Neurol 18:352-358

7. Blair N, Cremer PD, Tchan MC (2015) Urea cycle disorders: a life-threatening yet treatable cause of metabolic encephalopathy in adults. Pract Neurol 15:45-48

8. van der Knaap MS, Leegwater PA, Konst A et al (2002) Mutations in each of the five subunits of translation initiation factor eIF2B can cause leukoencephalopathy with vanishing white matter. Ann Neurol 51:264-270

9. Bugiani M, Vuong C, Breur M, van der Knaap MS (2018) Vanishing white matter: a leukodystrophy due to astrocytic dysfunction. Brain Pathol 28(3):408-421

10. van der Knaap MS, Pronk JC, Scheper GC (2006) Vanishing white matter disease. Lancet Neurol 5:413-423

11. Hamlton E, van der Lei HDW, Vermeulen G et al (2018) Natural history of vanishing white matter. Ann Neurol 84:274-288

12. Carra-Dalliere C, Horzinski L, Ayrignac X et al (2011) Natural history of adult-onset eIF2B-related disorders: a multicentric survey of 24 cases [in French]. Rev Neurol (Paris) 167:802-811

13. Abbink TEM, Wisse LE, Jaku E et al (2019) Vanishing white matter: deregulated integrated stress response as therapy target. Ann Clin Transl Neurol 6(8):1407-1422

14. Chabriat H, Joutel A, Dichgans M et al (2009) Cadasil. Lancet Neurol 8(7):643-653

15. Drazyk A, Tan RYY, Tay J et al (2019) Encephalopathy in a large cohort of British cerebral autosomal dominant arteriopathy with subcortical infarcts and leukoencephalopathy patients. Stroke 50:283-290

16. Feuerhake F, Volk B, Ostertag CB et al (2002) Reversible coma with raised intracranial pressure: an unusual clinical manifestation of CADASIL. Acta Neuropathol 103(2):188-192

17. Le Ber I, Carluer L, Derache N et al (2002) Unusual presentation of CADASIL with reversible coma and confusion. Neurology 59(7):1115-1116
18. Schon F, Martin RJ, Prevett M et al (2003) "CADASIL coma": an underdiagnosed acute encephalopathy. J Neurol Neurosurg Psychiatry 74:249-52

19. Eikermann-Haerter K, Yuzawa I, Dilekoz E et al (2011) Cerebral autosomal dominant arteriopathy with subcortical infarcts and leukoencephalopathy syndrome mutations increase susceptibility to spreading depression. Ann Neurol 69:413-418

20. Takahashi-Fujigasaki J (2003) Neuronal intranuclear hyaline inclusion disease. Neuropathology 23:351-359

21. Sone J, Mori K, Inagaki T et al (2016) Clinicopathological features of adult-onset neuronal intranuclear inclusion disease. Brain 139:3170-3186

22. Sone J, Kitagawa N, Sugawara E et al (2014) Neuronal intranuclear inclusion disease cases with leukoencephalopathy diagnosed via skin biopsy. J Neurol Neurosurg Psychiatry 85:354-356

23. Sone J, Tanaka F, Koike H et al (2011) Skin biopsy is useful for the antemortem diagnosis of neuronal intranuclear inclusion disease. Neurology 76:1372-1376

24. Fujita K, Osaki Y, Miyamoto R et al (2017) Neurologic attack and dynamic perfusion abnormality in neuronal intranuclear inclusion disease. Neurology Clin Practice 7(6):e39-e42

25. Tian Y, Wang JL, Huang W et al (2019) Expansion of humanspecific GGC repeat in neuronal intranuclear inclusion diseaserelated disorders. Am J Hum Genet 105(1):166-176

26. Deng J, Gu M, Miao Y et al (2019) Long-read sequencing identified repeat expansions in the 5'UTR of the NOTCH2NLC gene from Chinese patients with neuronal intranuclear inclusion disease. J Med Genet 56(11):758-764

27. Kleopa KA, Sargiannidou I (2015) Connexins, gap junctions and peripheral neuropathy. Neurosci Lett 596:27-32

28. Nicholson G, Corbett A (1996) Slowing of central conduction in X-linked Charcot- Marie-Tooth neuropathy shown by brain auditory evoked responses. J Neurol Neurosurg Psychiatry 61:43-46

29. Panas M, Karadimas C, Avramopoulos D et al (1998) Central nervous system involvement in four patients with Charcot-MarieTooth disease with connexin 32 extracellular mutations. J Neurol Neurosurg Psychiatry 65:947-948

30. Dubourg O, Tardieu S, Birouk N et al (2001) Clinical, electrophysiological and molecular genetic characteristics of 93 patients with X-linked Charcot-Marie-Tooth disease. Brain 124:1958-1967

31. Taylor R, Simon EM, Marks HG, et al. The CNS phenotype of $\mathrm{X}$-linked Charcot- Marie-Tooth disease. More than a peripheral problem. Neurology, (1 of 2) (2003) pp. 1475-1478

32. Paulson HL, Garbern JY, Hoban TF et al (2002) Transient central nervous system white matter abnormality in X-linked CharcotMarie-Tooth disease. Ann Neurol 52:429-434

33. Al-Mateen M, Craig AK, Chance PF (2014) The central nervous system phenotype of X-linked Charcot-Marie-Tooth disease: a transient disorder of children and young adults. J Child Neurol 29(3):342-8

34. Parissis D, Ioannidis P, Papadopoulos G et al (2017) CharcotMarie-Tooth Disease 1X Simulating Paraparetic Guillain-Barre Syndrome. Neurologist 22(6):234-236

35. Pan JJ, Zhao YY, Lu C et al (2015) Mild encephalitis/encephalopathy with a reversible splenial lesion: five cases and a literature review. Neurol Sci 36(11):2043-51

36. Vanderschueren G, Schotsmans K, Maréchal E et al (2018) Mild encephalitis with reversible splenial (MERS) lesion syndrome due to influenza B virus. Pract Neurol 18:391-392

37. Starkey J, Kobayashi N, Numaguchi Y et al (2017) Cytotoxic lesions of the corpus callosum that show restricted diffusion: mechanisms, causes and manifestations. Radiographics 37:562-576

38. Kurahashi H, Azuma Y, Masuda A et al (2018) MYRF is associated with encephalopathy with reversible myelin vacuolization. Ann Neurol 83:98-106 
39. Jensen TS, de Fine OB, Kraft M et al (1991) Familial hemiplegic migraine - a reappraisal and long-term follow up study. Cephalalgia 1:33-39

40. Fitzsimons RB, Wolfenden WH (1985) Migraine coma. Meningitic migraine with cerebral oedema associated with a new form of autosomal dominant cerebellar ataxia. Brain 108:555-77

41. Russell MB, Ducros A (2011) Sporadic and familial hemiplegic migraine: pathophysiological mechanisms, clinical characteristics, diagnosis, and management. Lancet Neurol 10:457-70

42. Pelzer N, Haan J, Stam AH et al (2018) Clinical spectrum of hemiplegic migraine and chances of finding a pathogenic mutation. Neurology 90(7):1-8

43. Ducros A, Denier C, Joutel A et al (2001) The clinical spectrum of familial hemiplegic migraine associated with mutations in a neuronal calcium channel. N Engl J Med 345:17-24

44. Jurkat-Rott K, Freilinger T, Dreier JP et al (2004) Variability of familial hemiplegic migraine with novel A1A2 $\mathrm{Na}(+) / \mathrm{K}(+)-$ ATPase variants. Neurology 62:1857-1861

45. Thomsen LL, Eriksen MK, Roemer SF et al (2002) A population-based study of familial hemiplegic migraine suggests revised diagnostic criteria. Brain 125:1379-1391

46. Stam AH, Luijckx GJ, Poll-The BT et al (2009) Early seizures and cerebral oedema after trivial head trauma associated with the CACNA1A S218L mutation. J Neurol Neurosurg Psychiatry 80:1125-1129

47. van den Maagdenberg AM, Pizzorusso T, Kaja S et al (2010) High cortical spreading depression susceptibility and migraineassociated symptoms in Ca (v) 2.1 S218L mice. Ann Neurol 67(1):85-98

48. Mizuguchi M, Abe J, Mikkaichi K et al (1995) Acute necrotising encephalopathy of childhood: a new syndrome presenting with multifocal, symmetric brain lesions. J Neurol Neurosurg Psychiatry 58:555-561

49. Dixon L, Varley J, Gontsarova A, Mallon D, Tona F, Muir D, Luqmani A, Jenkins H, Nicholas R, Jones B, Everitt A (2020) COVID-19-related acute necrotizing encephalopathy with brain stem involvement in a patient with aplastic anemia. Neurol Neuroimmunol Neuroinflamm 7(5):e789. https://doi.org/10.1212/ NXI.0000000000000789

50. Wu X, Wu W, Pan W, et al. Acute necrotizing encephalopathy: an underrecognized clinicoradiologic disorder. Mediators Inflamm (2015) pp. 1-10.

51. Kelly E, Harvey J, Brion K et al (2019) Relapsing necrotising encephalomyelopathy due to RANBP2 mutation. Pract Neurol 19(4):360-363

52. Lönnqvist $\mathrm{T}$, Isohanni $\mathrm{P}$, Valanne L et al (2011) Dominant encephalopathy mimicking mitochondrial disease. Neurology 76(1):101-103

53. Biswas A, Varman M, Gunturi A et al (2018) Teaching NeuroImages: Acute necrotizing encephalopathy of childhood. Neuroimaging findings Neurology 90(2): e177-e178

54. Neilson DE, Adams MD, Orr CMD et al (2009) Infection-triggered familial or recurrent cases of acute necrotizing encephalopathy caused by mutations in a component of the nuclear pore, RANBP2. Am J Hum Genet 84:44-51

55. Knijnenburg A, Nicolai J, Bok LA et al (2020) Acute encephalopathy after head trauma in a patient with a RHOBTB2 mutation. Neurology 6(3):e418. https://doi.org/10.1212/NXG.00000 00000000418

56. Brisse E, Wouters CH, Matthys P (2016) Advances in the pathogenesis of primary and secondary haemophagocytic lymphohistiocytosis: differences and similarities. Br J Haematol 174:203-217

57. Rosado FG, Kim A (2013) Hemophagocytic Lymphohistiocytosis: an Update on Diagnosis and Pathogenesis. Am J Clin Pathol 139:713-727
58. Deiva K, Mahlaoui N, Beaudonnet F et al (2012) CNS involvement at the onset of primary hemophagocytic lymphohistiocytosis. Neurology 78:1150-1156

59. Horne A, Wickström R, Jordan MB et al (2017) How to treat involvement of the central nervous system in hemophagocytic lymphohistiocytosis? Curr Treat Options Neurol 19(1):3. https:// doi.org/10.1007/s11940-017-0439-4

60. Benson L, Hojun Li, Henderson LA et al (2019) Pediatric CNSisolated hemophagocytic lymphohistiocytosis. Neurol Neuroimmunol Neuroinflamm 6(3):e560

61. Diprose WK, Jordan A, Anderson NE. Autoinflammatory syndromes in neurology: when our first line of defence misbehaves. Pract Neurol Published Online First: 01 October 2021. https://doi. org/10.1136/practneurol-2021-003031

62. Gorman G, Chinnery P, DiMauro S, Hirano M, Koga Y, McFarland R, Suomalainen A, Thorburn D, Zeviani M and Turnbull D. Mitochondrial diseases. Nature Reviews Disease Primers,2,(2016) pp. $1-22$

63. DiMauro S, Schon E, Carelli V, Hirano M (2013) The clinical maze of mitochondrial neurology. Nat Rev Neurol 9(8):429-444

64. Hirano M, Ricci E, Koenigsberger MR et al (1992) Melas: an original case and clinical criteria for diagnosis. Neuromuscul Disord 2(2):125-135

65. Omar Hikmat, Karin Naess, Martin Engvall, et al. Simplifying the clinical classification of polymerase gamma (POLG) disease based on age of onset; studies using a cohort of 155 cases. J Inherit Metab Dis, (2020) pp. 1-11

66. Tzoulis C, Bindoff L (2012) Acute mitochondrial encephalopathy reflects neuronal energy failure irrespective of which genome the genetic defect affects. Brain 135:3627-3634

67. CesarAlves APF, Teixeira SR, Martin-Saavedra JS et al (2020) Pediatric Leigh Syndrome: Neuroimaging Features and Genetic Correlations. Ann Neurol 88:218-232

68. Ng YS, Bindoff LA, Gorman GS, et al. Consensus-based statements for the management of mitochondrial stroke-like episodes. Wellcome Open Res, (Dec 13) 4: (2019) pp. 201. eCollection

69. Finsterer J, Aliyev R (2020) Metabolic stroke or stroke-like lesion: peculiarities of a phenomenon. J Neurol Sci 412(May):116726. https://doi.org/10.1016/j.jns.2020.116726

70. Aurangzeb S, Vale T, Tofaris G et al (2014) Mitochondrial encephalomyopathy with lactic acidosis and stroke-like episodes (MELAS) in the older adult. Pract Neurol 14:432-436

71. Finsterer J (2019) Mitochondrial metabolic stroke: phenotype and genetics of stroke- like episodes. J Neurol Sci 400:135-141

72. Yi Shiau Ng, Grainne S Gorman, Doug M Turnbull, et al. The diagnosis of posterior reversible encephalopathy syndrome. Lancet Neurology, (14 November) (2015) pp. 1073

73. Tzoulis C, Tran GT, Coxhead J et al (2014) Molecular pathogenesis of polymerase gamma-related neurodegeneration. Ann Neurol 76:66-81

74. Ohama E, Ohara S, Ikuta F, Tanmaka K, Nishiwaza M, Miyatake T (1987) Mitochondrial angiopathy in cerebral blood vessels of mitochondrial encephalomyopathy. Acta Neuropathol 74:226-233

75. Yamashita S, Nishino I, Nonaka I, Goto Y (2008) Genotype and phenotype analyses in 136 patients with single large-scale mitochondrial DNA deletions. J Hum Genet 53:598-606

76. Lonnqvist T, Paetau A, Valanne L, Pihko H (2009) Recessive twinkle mutations cause severe epileptic encephalopathy. Brain 132(Pt 6):1553-1562

77. Debray FG, Morin C, Janvier A, Villeneuve J, Maranda B (2011) Laframboise $\mathrm{R}$ et al LRPPRC mutations cause a phenotypically distinct form of Leigh syndrome with cytochrome c oxidase deficiency. J Med Genet 48:183-189

78. Zaganas I, Latsoudis H, Papadaki E, Vorgia P, Spilioti M, Plaitakis A (2009) A8344G tRNALys mutation associated with recurrent brain stem stroke-like episodes. J Neurol 256:271-273 
79. Bosch AM, Kamsteeg EJ, Rodenburg RJ, van Deutekom AW, Buis DR, Engelen M, Cobben JM (2018) Coenzyme Q10 deficiency due to a COQ4 gene defect causes childhood-onset spinocerebellar ataxia and stroke-like episodes. Mol Genet Metab Rep 17:19-21

80. Finsterer J (2020) The metabolic hypothesis is more likely than the epileptogenic hypothesis to explain stroke-like lesions. Wellcome Open Res 5:51

81. Tzoulis C, Henriksen E, Miletic H et al (2017) No evidence of ischemia in stroke-like lesions of mitochondrial POLG encephalopathy. Mitochondrion 32:10-15

82. Nesbitt V, Pitceathly RD, Turnbull DM et al (2013) The UK MRC mitochondrial disease patient cohort study: clinical phenotypes associated with the m.3243A $>\mathrm{G}$ mutation-- implications for diagnosis and management. J Neurol Neurosurg Psychiatry 84(8):936-8

83. Hakonen AH, Davidzon G, Salemi R (2007) Abundance of the POLG disease mutations in Europe, Australia, New Zealand, and the United States explained by single ancient European founders. Eur J Hum Genet 15(7):779-83

Publisher's Note Springer Nature remains neutral with regard to jurisdictional claims in published maps and institutional affiliations. 